\title{
Study conclude that TXA in severely injured was associated with lower mortality: beware of potential confounders
}

\author{
Patrick M. Honore ${ }^{1 *}$, Sebastien Redant ${ }^{1}$, Thierry Preseau ${ }^{2}$, Sofie Moorthamers ${ }^{2}$, Keitiane Kaefer ${ }^{1}$, \\ Leonel Barreto Gutierrez ${ }^{1}$, Rachid Attou ${ }^{1}$, Andrea Gallerani ${ }^{1}$, Willem Boer ${ }^{3}$ and David De Bels ${ }^{1}$
}

With great interest, we read the recently published article by Imach et al. who concluded that tranexamic acid (TXA) use in severely injured patients was associated with a significantly lower risk of massive transfusion and lower mortality in the early in-hospital treatment period, based on matched pairing using the nationwide German Trauma Register DGU ${ }^{\circledR}$ [1]. When comparing the data between the two groups (with and without TXA), we observe that patients receiving TXA received significantly more hemostatic agents than the non TXA group $(47.8 \%$ vs $44.2 \%, p$ value $=0.018)$ [1]. Hemostatic agents comprised fibrinogen, prothrombin concentrates (PPSB), calcium, factor VII or factor XIII which are all major players in coagulation after severe trauma, particularly fibrinogen [1]. All patients in the database, either with or without TXA in the matched pairs table, had an injury severity score (ISS) above 25 [1]. Life-threatening coagulopathy is present in almost all patients with an ISS $>25$ with hypotension, hypothermia, and acidosis [2]. Severe hypofibrinogenemia $(<100 \mathrm{mg} / \mathrm{dl})$ is also a frequent finding in trauma with an ISS score above 25 [2]. In patients with disrupted coagulation in severe trauma with an ISS above 25, PPSB and factors VII are crucial [3]. An advisory board comprising European trauma experts (2019) defining trauma-induced coagulopathy (TIC) in patients corresponding to those studied by Imach et al. (with an

This comment refers to the article available online at https://doi.org/10.1186/ s13054-021-03701-7.

*Correspondence: Patrick.Honore@CHU-Brugmann.be

${ }^{1}$ ICU Department, Centre Hospitalier Universitaire Brugmann-Brugmann

University Hospital, Faculty of Medicine, ULB University, Place Van

Gehuchtenplein, 4, 1020 Brussels, Belgium

Full list of author information is available at the end of the article
ISS > 25), recommended fibrinogen concentrate, and not fresh frozen plasma (FFP), as first-line therapy for TIC [3]. In case of further bleeding, prothrombin complex concentrate (PCC) should be given [3]. In another study, after meeting certain criteria (hemoglobin $>8 \mathrm{~g} / \mathrm{dl}$, serum fibrinogen $\geq 1.0 \mathrm{~g} / \mathrm{l}$, platelets $>50,000$, arterial $\mathrm{pH} \geq 7.20$, and body temperature $\geq 34{ }^{\circ} \mathrm{C}$ ) recombinant factor VII was associated with a significantly lower mortality [4].

The fact that severe trauma patients with TXA received significantly more hemostatic agents (fibrinogen, PPSB, calcium, factor VII or factor XIII) as compared to nonTXA severe trauma patients should therefore be seen as an important potential confounding factor, reducing the solidity of the data published by Imach et al.

\section{Response to letter: Study conclude that TXA in severely injured was associated with lower mortality: beware of potential confounders}
Sebastian Imach ${ }^{4 *}$, Arasch Wafaisade ${ }^{4}$, Rolf Lefering ${ }^{5}$,
Andreas Böhmer ${ }^{6}$, Mark Schieren ${ }^{6}$, Victor Suárez ${ }^{7,8}$,
Matthias Fröhlich ${ }^{4}$ and TraumaRegister DGU ${ }^{9}$
*Correspondence: Dr.Imach@gmx.de; imachse@kliniken-koeln.de
${ }^{4}$ Department of Trauma and Orthopedic Surgery, Cologne-Merheim
Medical
Center (CMMC), University Witten/Herdecke, Cologne, Germany
${ }^{5}$ Institute for Research in Operative Medicine (IFOM), University Witten/Herd ecke, Cologne, Germany
${ }^{6}$ Department of Anaesthesiology and Intensive Care Medicine, Cologne-Mer heim Medical Center (CMMC), University Witten/Herdecke, Cologne, Germany. ${ }^{7}$ Department II of Internal Medicine (Nephrology, Rheumatology, Diabetes and General Internal Medicine) and Center for Molecular Medicine Cologne, University of Cologne, Faculty of Medicine, Cologne, Germany
${ }^{8}$ University Hospital Cologne, Cologne, Germany. ${ }^{9}$ Committee on Emergency Medicine, Intensive Care and Trauma Management (Sektion NIS) of the Ger man Trauma Society (DGU), Berlin, Germany

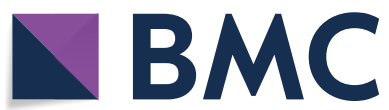

(c) The Author(s) 2021. Open Access This article is licensed under a Creative Commons Attribution 4.0 International License, which permits use, sharing, adaptation, distribution and reproduction in any medium or format, as long as you give appropriate credit to the original author(s) and the source, provide a link to the Creative Commons licence, and indicate if changes were made. The images or other third party material in this article are included in the article's Creative Commons licence, unless indicated otherwise in a credit line to the material. If material is not included in the article's Creative Commons licence and your intended use is not permitted by statutory regulation or exceeds the permitted use, you will need to obtain permission directly from the copyright holder. To view a copy of this licence, visit http://creativecommons.org/licenses/by/4.0/. The Creative Commons Public Domain Dedication waiver (http://creativeco mmons.org/publicdomain/zero/1.0/) applies to the data made available in this article, unless otherwise stated in a credit line to the data. 
We would like to thank Honore et al. for their critical appreciation of our work. They have legitimately dealt with the potential main confounder of our study [1]. The aim of our work was to investigate the effects of preclinical administration of TXA in severely injured patients (ISS TXA 32.4 SD 14.7, Control 32.0 SD 14.7) in a developed healthcare system. In those systems, the sole administration of TXA is not expected to be the only therapeutic measure that is taken in the care for a severely injured patient. The patients in the study did not all meet the conditions for life-threatening coagulopathy defined by Haas and Cushing [2]. Only $24.6 \%$ in the TXA group have been in shock $((\mathrm{BP} \leq 90 \mathrm{mmHg})$ at hospital admission. Mean base excess as a parameter representing potential acidosis was $-4.5 \mathrm{mmol} / \mathrm{l}$ (SD 6.1) in TXA (Control-4.3(6.3)). We had no data concerning body temperature. Consequently, the use of coagulation factors does not seem to be mandatory for every patient because of an expected life-threatening coagulopathy. However, we agree that a trauma-induced coagulopathy (TIC) should be treated by hemostatic agents [3]. This database represents the standard of care in Germany with Fresh Frozen Plasma being a part of it. In the literature, at least indications can be found in the case of mass transfusions [5].

The previously cited work by Černý et al. calls for the avoidance of mass transfusion protocols (MTP) as the main goal of therapy and recommends the immediate administration of TXA. In your study, preclinical administration of TXA seems to trigger a more comprehensive resuscitation approach in the early hospital phase since TXA group received more i.v. fluids, blood transfusion were started more frequently and more hemostatic drugs were administrated. The trigger for this approach remains unclear, as the collective was matched for the usual triggers (BP, trauma mechanism, injury severity). This approach undoubtedly begins with the preclinical administration of TXA. The suspected risk of bleeding can be an explanation for this. The search for further measurable triggers of therapy should be a future research interest but cannot be answered by our database.

\section{Abbreviations}

TXA: Tranexamic acid; PPSB: Prothrombin concentrates; ISS: Injury severity score; TIC: Trauma-induced coagulopathy; FFP: Fresh frozen plasma; PCCs: Prothrombin complex concentrates; BP: Blood pressure; MTP: Mass transfusion protocol.

\section{Acknowledgements}

None.
Authors' contributions

PMH, SM, SR, WB, DDB designed the paper. All authors participated in drafting and reviewing. All authors read and approved the final version of the manuscript.

\section{Funding}

None.

Availability of data and materials

Not applicable.

\section{Declarations}

Ethics approval and consent to participate

Not applicable.

Consent for publication

Not applicable.

Competing interests

The authors declare that they have no competing interests.

\section{Author details}

${ }^{1}$ ICU Department, Centre Hospitalier Universitaire Brugmann-Brugmann University Hospital, Faculty of Medicine, ULB University, Place Van Gehuchtenplein, 4, 1020 Brussels, Belgium. ${ }^{2}$ ED Department, Centre Hospitalier Universitaire Brugmann, Brussels, Belgium. ${ }^{3}$ Intensive Care Department, Ziekenhuis Oost Limburgh, Campus St Jan, Genk, Belgium.

Received: 28 September 2021 Accepted: 29 September 2021

Published online: 01 November 2021

\section{References}

1. Imach S, Wafaisade A, Lefering R, et al. TraumaRegister DGU. The impact of prehospital tranexamic acid on mortality and transfusion requirements: match-pair analysis from the nationwide German TraumaRegister DGU ${ }^{\circledR}$. Crit Care. 2021;25(1):277. https://doi.org/10.1186/ s13054-021-03701-7.

2. Haas T, Cushing MM. Hemostatic balance in severe trauma. Front Pediatr. 2020;11(8): 600501. https://doi.org/10.3389/fped.2020.600501.

3. Černý V, Maegele M, Agostini V, et al. Variations and obstacles in the use of coagulation factor concentrates for major trauma bleeding across Europe: outcomes from a European expert meeting. Eur J Trauma Emerg Surg. 2021. https://doi.org/10.1007/s00068-020-01563-2.

4. Payen JF, Berthet M, Genty C, et al. Novoseven Trauma Investigators. Reduced mortality by meeting guideline criteria before using recombinant activated factor VII in severe trauma patients with massive bleeding. Br J Anaesth. 2016;117(4):470-6. https://doi.org/10.1093/bja/aew276.

5. Holcomb JB, Tilley BC, Baraniuk S, et al. Transfusion of plasma, platelets, and red blood cells in a 1:1:1 vs a 1:1:2 ratio and mortality in patients with severe trauma: the PROPPR randomized clinical trial. JAMA. 2015;313(5):471-82.

\section{Publisher's Note}

Springer Nature remains neutral with regard to jurisdictional claims in published maps and institutional affiliations. 